\title{
Comparison of cardiovascular risk profiles among ethnic groups using population health surveys between 1996 and 2007
}

\author{
Maria Chiu MSc, Peter C. Austin PhD, Douglas G. Manuel MD MSc, Jack V. Tu MD PhD
}

Previously published at www.cmaj.ca

\section{ABSTRACT}

Background: Although people of South Asian, Chinese and black ethnic backgrounds represent about $60 \%$ of the world's population, most knowledge of cardiovascular risk is derived from studies conducted in white populations. We conducted a large, population-based comparison of cardiovascular risk among people of white, South Asian, Chinese and black ethnicity living in Ontario, Canada.

Methods: We examined the age- and sex-standardized prevalence of eight cardiovascular risk factors, heart disease and stroke among 154653 white people, 3364 South Asian people, 3038 Chinese people and 2742 black people. For this study, we pooled respondent data from five crosssectional health surveys conducted between 1996 and 2007: the National Population Health Survey of 1996 and the Canadian Community Health Survey, versions 1.1, 2.1, 3.1 and 4.1 .

Results: The four ethnic groups varied considerably in the prevalence of the four major cardiovascular risk factors that we examined: for smoking, South Asian 8.6\%, Chinese $8.7 \%$, black $11.4 \%$ and white $24.8 \%$; for obesity, Chinese 2.5\%, South Asian $8.1 \%$, black $14.1 \%$ and white $14.8 \%$; for diabetes mellitus, white $4.2 \%$, Chinese $4.3 \%$, South Asian $8.1 \%$ and black $8.5 \%$; and for hypertension, white $13.7 \%$, Chinese $15.1 \%$, South Asian $17.0 \%$ and black $19.8 \%$. The prevalence of heart disease ranged from a low of $3.2 \%$ in the Chinese population to a high of $5.2 \%$ in the South Asian population, and the prevalence of stroke ranged from a low of $0.6 \%$ in the Chinese population to a high of $1.7 \%$ in the South Asian population. Although the black population had the least favourable cardiovascular risk factor profile overall, this group had a relatively low prevalence of heart disease (3.4\%).

Interpretation: Ethnic groups living in Ontario had striking differences in cardiovascular risk profiles. Awareness of these differences may help in identifying priorities for the development of cardiovascular disease prevention programs for specific ethnic groups.
$\mathrm{C}$ ardiovascular diseases, including stroke, are the leading causes of death worldwide. Evidence from mortality studies suggests that the global burden of cardiovascular diseases is not shared equally across nations. ${ }^{1,2}$ However, little is known about the relative distribution of cardiovascular risk factors and conditions across the world's four largest ethnic groups: white, South Asian, Chinese and black. Previous studies have documented differences in cardiovascular health across two or three ethnic groups, e.g., a higher risk of diabetes mellitus among South Asian people relative to the general population in Canada and the United Kingdom, ${ }^{3,4}$ and a higher risk of hypertension and stroke in the black population than the white population in the United States. ${ }^{5}$ These earlier studies were mostly conducted in different social macro-environments, under different health care systems and with differences in access to health care. Smoking, obesity, diabetes, hypercholesterolemia and hypertension account for most of the risk for heart disease worldwide. ${ }^{6}$ However, no published studies have compared the distribution of traditional cardiovascular risk factors and associated prevalence of heart disease and stroke across these four ethnic groups residing within the same social macro-environment and with similar access to health care.

With over 1.8 million people of South Asian, Chinese or black descent and about 9.1 million people of European descent, ${ }^{7}$ Ontario provides an ideal setting to study cardiovascular health across ethnic groups living within a relatively homogenous environment. Because many cardiovascular risk factors may be influenced by the environment in which one lives (e.g., smoking rates are influenced by cigarette prices and antismoking legislation, and obesity rates are influenced by the availability of healthy foods and the nature of the built environment), comparing the prevalence of risk factors

From the Institute for Clinical Evaluative Sciences (Chiu, Austin, Manuel, Tu), Toronto, Ont.; the Institute of Medical Science (Chiu, Tu) and the Dalla Lana School of Public Health (Austin, Tu), University of Toronto, Toronto, Ont. the Division of Cardiology, Schulich Heart Centre, Department of Medicine (Tu), Sunnybrook Health Sciences Centre, Toronto, Ont.; Ottawa Hospital Research Institute (Manuel); and Statistics Canada (Manuel), Ottawa, Ont.

CMAJ 2010. DOI:10.1503/cmaj.091676 
among different groups living within the same social macroenvironment allows true ethnic differences in cardiovascular risk profiles to be identified.

In this study, we compared the prevalence of eight cardiovascular risk factors and the prevalence of heart disease and stroke in a population-based sample of white, South Asian, Chinese and black people living in Ontario. We also examined prevalence estimates by age and sex to identify the subgroups at highest risk for specific cardiovascular risk factors and diseases.

\section{Methods}

\section{Data sources and study population}

We used data gathered from the Ontario participants in Statistics Canada's cross-sectional National Population Health Survey (1996) and Canadian Community Health Survey, cycles 1.1 (2001), 2.1 (2003), 3.1 (2005) and 4.1 (2007). The cross-sectional National Population Health Survey was replaced by the Canadian Community Health Survey in 2001; the survey methods, however, remained largely consistent. Details about the methodology of these two surveys are described elsewhere. ${ }^{8}$ Briefly, they used a consistent multistage stratified cluster sampling strategy to collect selfreported socio-demographic and health-related information from a representative sample of persons living in private dwellings. The individual response rates for these government-funded surveys ranged from $75.1 \%$ to $94.4 \%$. The surveys were conducted by highly skilled interviewers in over 25 languages.

In this study, we analyzed data for people living in Ontario who were 12 years of age or older and who identified themselves, when asked to which "racial or cultural" group they belonged, as white, South Asian (i.e., of Indian, Pakistani, Bangladeshi or Sri Lankan origin), Chinese (i.e., mainly from China and Hong Kong) or black (i.e., of African or Caribbean descent). We combined data from the five survey cycles and included survey questions that were consistent across cycles over the survey period from 1996 to $2007 .{ }^{9}$

\section{Study variables}

Socio-demographic characteristics were age, sex, marital status, highest level of education attained in the household and by the individual, household and individual income in Canadian dollars, and urban versus rural dwelling. Using annual household income and household size, we estimated income adequacy (i.e., lowest, lower-middle, upper-middle and highest income) as a four-level measure of socio-economic status, as defined by Statistics Canada. ${ }^{10,11}$

We analyzed a total of eight cardiovascular risk factors: four major risk factors (current smoking, obesity, diabetes and hypertension) and four other risk factors (psychosocial stress, inadequate consumption of fruits and vegetables, inadequate physical activity and nonregular alcohol consumption). We also examined two cardiovascular conditions: heart disease (which included angina, myocardial infarction and congestive heart failure) and stroke. Diabetes, hypertension, heart disease and stroke were self- reported physician-diagnosed conditions. Obesity was defined as body mass index (calculated from self-reported weight and height) of at least 30 . Psychosocial stress was defined as the individual's self assessment of stress on most days: "extremely" or "quite a bit" v. "not at all," "not very" or "a bit." Inadequate intake of fruits and vegetables was defined as eating fruits or vegetables less than three times a day and inadequate physical activity was defined as participating in no more than 15 minutes of leisure time physical activity per day (e.g., walking for exercise, jogging, swimming, bicycling).$^{10,12}$ Nonregular alcohol consumption was defined as fewer than three drinks per week. ${ }^{6}$ We calculated the percentage of the population with two or more of the four major cardiovascular risk factors and used this composite measure to rank the risk factor profiles of the ethnic groups from most to least favourable.

\section{Statistical analyses}

We calculated the age- and sex-standardized prevalence of socio-demographic characteristics, cardiovascular risk factors and cardiovascular diseases for each of the four ethnic groups using the direct standardization method with five-year age bands and the 2001 Ontario census as the standard population. Each ethnic-specific prevalence estimate was compared with that for the overall study population and that for the white group. Relative differences and ratios were calculated using exact statistics, rather than the rounded values that are reported in the tables. To examine whether ethnic differences in cardiovascular risk varied by age and sex, we stratified participants by sex and categorized them according to the following age groups: $12-19,20-44,45-64$ and $\geq 65$ years.

For all analyses, we weighted the data using Statistics Canada's sample weights to account for the complex survey sampling design and to allow for study results to be representative of the overall population of Ontario between 1996 and 2007. We used bootstrap methods to test statistical significance. The $p$ value was derived using the appropriate $z$ test. ${ }^{13,14}$ All tests were two-sided, and $p<0.05$ was considered statistically significant. Additional details on the bootstrap methods are reported in Appendix 1 (available online at www.cmaj.ca /cgi/content/full/cmaj.091676/DC1). ${ }^{15}$

\section{Ethics committee approval}

The analysis, for the purposes of this study, of the Ontario data from the national surveys was approved by the Research Ethics Board at Sunnybrook Health Sciences Centre. Statistics Canada obtained informed consent from all survey participants at the time of the original surveys.

\section{Results}

\section{Study population}

We analyzed data for a total of 163797 survey participants: 154653 of white background, 3364 of South Asian background, 3038 of Chinese background and 2742 of black background) over the five population-based survey cycles. The distribution of the four ethnic groups in the weighted survey population was representative of the 2001 Ontario census. ${ }^{16}$ 


\section{Socio-demographic characteristics}

The mean age of the study population was 42.3 years, and $49.1 \%$ of the participants were male (Table 1). We standardized the survey data by age and sex across ethnic groups so that differences in responses would reflect ethnic differences, rather than differences in the age and sex distribution of the respondents. In general, South Asian and Chinese respondents were most likely to report having a college or university degree, and white respondents had the most favourable income adequacy.
Cardiovascular risk factors, heart disease and stroke

We found large differences among the ethnic groups in the prevalence of major cardiovascular risk factors: for smoking, South Asian $8.6 \%$, Chinese $8.7 \%$, black $11.4 \%$ and white $24.8 \%$; for obesity, Chinese $2.5 \%$, South Asian $8.1 \%$, black $14.1 \%$ and white $14.8 \%$; for diabetes, white $4.2 \%$, Chinese 4.3\%, South Asian $8.1 \%$ and black $8.5 \%$; and for hypertension, white $13.7 \%$, Chinese $15.1 \%$, South Asian $17.0 \%$ and black 19.8\%) (Table 2). Age- and sex-standardized mean body mass index was lowest among the Chinese respondents

Table 1: Age- and sex-standardized prevalence of socio-demographic characteristics, by ethnic group, Ontario, Canada, 1996-2007 $(n=163797)^{*}$

\begin{tabular}{|c|c|c|c|c|c|c|c|c|c|}
\hline \multirow[b]{2}{*}{ Characteristic } & \multirow{2}{*}{$\begin{array}{c}\text { Overall } \\
n=163797 \\
\text { Prevalence, \% }\end{array}$} & \multicolumn{2}{|c|}{$\begin{array}{c}\text { White } \\
n=154653\end{array}$} & \multicolumn{2}{|c|}{$\begin{array}{c}\text { South Asian } \\
n=3364\end{array}$} & \multicolumn{2}{|c|}{$\begin{array}{l}\text { Chinese } \\
n=3038\end{array}$} & \multicolumn{2}{|c|}{$\begin{array}{c}\text { Black } \\
n=2742\end{array}$} \\
\hline & & Prevalence, \% & $p \dagger$ & Prevalence, \% & $p \dagger$ & Prevalence, \% & $p \dagger$ & Prevalence, \% & $p \dagger$ \\
\hline Age, yr, mean & 42.3 & 42.3 & 0.77 & 42.2 & 0.043 & 42.3 & 0.70 & 42.3 & 0.44 \\
\hline Sex, male & 49.1 & 49.1 & 1.00 & 49.1 & 1.00 & 49.1 & 1.00 & 49.1 & 1.00 \\
\hline \multicolumn{10}{|l|}{ Marital status } \\
\hline Separated & 2.4 & 2.4 & 0.39 & 1.4 & 0.001 & 0.6 & $<0.001$ & 4.9 & $<0.001$ \\
\hline Widowed & 5.3 & 5.2 & 0.61 & 6.8 & 0.002 & 5.1 & 0.68 & 5.2 & 0.97 \\
\hline $\begin{array}{l}\text { Single, never } \\
\text { married }\end{array}$ & 30.2 & 30.0 & 0.07 & 25.8 & $<0.001$ & 32.0 & 0.003 & 39.1 & $<0.001$ \\
\hline Common-law & 5.3 & 5.9 & $<0.001$ & 0.7 & $<0.001$ & 0.9 & $<0.001$ & 4.5 & 0.17 \\
\hline $\begin{array}{l}\text { Less than high } \\
\text { school } \\
\text { graduation }\end{array}$ & 7.5 & 7.7 & 0.16 & 5.1 & $<0.001$ & 4.9 & $<0.001$ & 7.6 & 0.94 \\
\hline $\begin{array}{l}\text { High school } \\
\text { graduation }\end{array}$ & 12.7 & 12.9 & 0.07 & 10.0 & 0.001 & 11.5 & 0.21 & 11.3 & 0.17 \\
\hline $\begin{array}{l}\text { Some } \\
\text { postsecondary }\end{array}$ & 6.0 & 6.0 & 0.90 & 6.1 & 0.94 & 4.4 & 0.004 & 8.2 & 0.022 \\
\hline $\begin{array}{l}\text { College or } \\
\text { university } \\
\text { degree }\end{array}$ & 73.8 & 73.4 & 0.044 & 78.8 & $<0.001$ & 79.2 & $<0.001$ & 73.0 & 0.59 \\
\hline $\begin{array}{l}\text { Annual household } \\
\text { income, mean, \$ }\end{array}$ & 76564 & 78930 & $<0.001$ & 63886 & $<0.001$ & 66954 & $<0.001$ & 54428 & $<0.001$ \\
\hline \multicolumn{10}{|l|}{$\begin{array}{l}\text { Income adequacy } \\
\text { group } \neq\end{array}$} \\
\hline 2 (lower-mid) & 18.8 & 17.7 & $<0.001$ & 28.5 & $<0.001$ & 22.1 & 0.004 & 27.7 & $<0.001$ \\
\hline 3 (mid-higher) & 34.2 & 34.3 & 0.63 & 33.1 & 0.38 & 32.9 & 0.33 & 33.9 & 0.83 \\
\hline 4 (highest) & 39.1 & 40.9 & $<0.001$ & 26.5 & $<0.001$ & 33.9 & $<0.001$ & 21.9 & $<0.001$ \\
\hline $\begin{array}{l}\text { Living in urban } \\
\text { area }\end{array}$ & 70.9 & 68.8 & $<0.001$ & 86.3 & $<0.001$ & 86.6 & $<0.001$ & 82.2 & $<0.001$ \\
\hline
\end{tabular}

*Data were derived from the Ontario components of Statistics Canada's National Population Health Survey and Canadian Community Health Surveys. Estimates were age- and sex-standardized to the 2001 Ontario Census population using five-year age categories and were weighted by the survey sample weight. tBootstrap methods were used to derive $p$ values for comparisons of estimates for specific ethnic groups with estimates for the entire study population.

fUsing annual household income and household size, income adequacy was estimated as a four-level measure of socio-economic status as defined by Statistics Canada. ${ }^{10,11}$ 
Table 2: Age- and sex-standardized prevalence of cardiovascular risk factors, by ethnic group, Ontario, Canada, 1996-2007 $(n=163797) *$

\begin{tabular}{|c|c|c|c|c|c|c|c|c|c|}
\hline \multirow[b]{2}{*}{ Risk factor } & \multirow{2}{*}{$\begin{array}{c}\text { Overall } \\
n=163797 \\
\text { Prevalence, \% }\end{array}$} & \multicolumn{2}{|c|}{$\begin{array}{c}\text { White } \\
n=154653\end{array}$} & \multicolumn{2}{|c|}{$\begin{array}{l}\text { South Asian } \\
n=3364\end{array}$} & \multicolumn{2}{|c|}{$\begin{array}{l}\text { Chinese } \\
n=3038\end{array}$} & \multicolumn{2}{|c|}{$\begin{array}{c}\text { Black } \\
n=2742\end{array}$} \\
\hline & & Prevalence, \% & $p \dagger$ & Prevalence, \% & $p \dagger$ & Prevalence, \% & $p \dagger$ & Prevalence, \% & pt \\
\hline \multicolumn{10}{|l|}{ Sex, no. } \\
\hline Male & 74978 & 70555 & & 1741 & & 1468 & & 1214 & \\
\hline Female & 88819 & 84098 & & 1623 & & 1570 & & 1528 & \\
\hline \multicolumn{10}{|c|}{ Major risk factors } \\
\hline \multicolumn{10}{|c|}{ Current smoking } \\
\hline All & 22.7 & 24.8 & $<0.001$ & 8.6 & $<0.001$ & 8.7 & $<0.001$ & 11.4 & $<0.001$ \\
\hline Male & 25.2 & 25.2 & 1.00 & 13.8 & $<0.001$ & 14.4 & $<0.001$ & 15.4 & $<0.001$ \\
\hline Female & 20.3 & 20.3 & 1.00 & 3.6 & $<0.001$ & 3.3 & $<0.001$ & 7.6 & $<0.001$ \\
\hline \multicolumn{10}{|l|}{ Obesity $\neq$} \\
\hline All & 14.0 & 14.8 & $<0.001$ & 8.1 & $<0.001$ & 2.5 & $<0.001$ & 14.1 & 0.91 \\
\hline Male & 14.9 & 14.9 & 1.00 & 7.8 & $<0.001$ & 2.5 & $<0.001$ & 11.2 & 0.003 \\
\hline Female & 13.1 & 13.1 & 1.00 & 8.5 & $<0.001$ & 2.6 & $<0.001$ & 16.8 & 0.008 \\
\hline \multicolumn{10}{|c|}{ Diabetes mellitus } \\
\hline All & 4.5 & 4.2 & $<0.001$ & 8.1 & $<0.001$ & 4.3 & 0.77 & 8.5 & $<0.001$ \\
\hline Male & 4.8 & 4.8 & 1.00 & 9.4 & $<0.001$ & 4.0 & 0.28 & 7.4 & 0.026 \\
\hline Female & 4.1 & 4.1 & 1.00 & 6.8 & 0.010 & 4.6 & 0.61 & 9.5 & $<0.001$ \\
\hline \multicolumn{10}{|c|}{ Hypertension } \\
\hline All & 14.0 & 13.7 & 0.014 & 17.0 & 0.001 & 15.1 & 0.19 & 19.8 & $<0.001$ \\
\hline Male & 13.1 & 13.1 & 1.00 & 16.0 & 0.022 & 14.4 & 0.26 & 17.7 & 0.002 \\
\hline Female & 14.8 & 14.8 & 1.00 & 17.9 & 0.022 & 15.8 & 0.45 & 21.7 & $<0.001$ \\
\hline \multicolumn{10}{|l|}{ Composite§ } \\
\hline All & 9.8 & 10.1 & $<0.001$ & 7.9 & 0.023 & 4.3 & $<0.001$ & 11.1 & 0.13 \\
\hline Male & 10.3 & 10.3 & 1.00 & 9.3 & 0.40 & 4.5 & $<0.001$ & 10.5 & 0.88 \\
\hline Female & 9.2 & 9.2 & 1.00 & 6.6 & 0.016 & 4.1 & $<0.001$ & 11.7 & 0.05 \\
\hline Rank** & & 3 & & 2 & & 1 & & 4 & \\
\hline \multicolumn{10}{|c|}{ Other risk factors } \\
\hline \multicolumn{10}{|c|}{ Psychosocial stress } \\
\hline All & 23.1 & 23.6 & 0.034 & 21.5 & 0.15 & 19.2 & $<0.001$ & 19.4 & 0.003 \\
\hline Male & 21.9 & 21.9 & 1.00 & 22.3 & 0.80 & 18.8 & 0.046 & 18.2 & 0.042 \\
\hline Female & 24.4 & 24.4 & 1.00 & 20.8 & 0.022 & 19.7 & $<0.001$ & 20.5 & 0.033 \\
\hline \multicolumn{10}{|c|}{$\begin{array}{l}\text { Inadequate fruit } \\
\text { and vegetablesł }\end{array}$} \\
\hline All & 22.1 & 22.1 & 0.81 & 19.2 & 0.006 & 24.0 & 0.13 & 24.4 & 0.10 \\
\hline Male & 26.6 & 26.6 & 1.00 & 22.5 & 0.007 & 28.1 & 0.44 & 30.0 & 0.12 \\
\hline Female & 17.8 & 17.8 & 1.00 & 16.0 & 0.24 & 20.0 & 0.16 & 18.9 & 0.50 \\
\hline \multicolumn{10}{|c|}{$\begin{array}{l}\text { Inadequate } \\
\text { physical activity }\end{array}$} \\
\hline All & 63.9 & 62.7 & $<0.001$ & 72.8 & $<0.001$ & 72.8 & $<0.001$ & 68.3 & $<0.001$ \\
\hline Male & 63.1 & 63.1 & 1.00 & 70.3 & $<0.001$ & 71.0 & $<0.001$ & 65.2 & 0.25 \\
\hline Female & 64.7 & 64.7 & 1.00 & 75.2 & $<0.001$ & 74.6 & $<0.001$ & 71.3 & $<0.001$ \\
\hline \multicolumn{10}{|c|}{$\begin{array}{l}\text { Nonregular alcohol } \\
\text { consumptionf }\end{array}$} \\
\hline All & 68.5 & 65.5 & $<0.001$ & 89.0 & $<0.001$ & 91.2 & $<0.001$ & 85.3 & $<0.001$ \\
\hline Male & 59.0 & 59.0 & 1.00 & 81.8 & $<0.001$ & 86.5 & $<0.001$ & 77.1 & $<0.001$ \\
\hline Female & 77.6 & 77.6 & 1.00 & 96.0 & $<0.001$ & 95.8 & $<0.001$ & 93.1 & $<0.001$ \\
\hline
\end{tabular}

*Data were derived from the Ontario components of Statistics Canada's National Population Health Survey and Canadian Community Health Surveys. Estimates were age- and sex-standardized to the 2001 Ontario Census population using five-year age categories and were weighted by the survey sample weight.

tBootstrap methods were used to derive $p$ values comparing ethnic-specific estimates with overall estimates.

$\ddagger$ Obesity, body mass index $\geq 30$; inadequate fruit and vegetable intake, < three times per day; inadequate physical activity, $\leq 15$ min/day; nonregular alcohol consumption, < three drinks per week.

$\S$ Percent with two or more major risk factors.

$\star * 1$ = most favourable, 4 = least favourable. 
(22.3), followed by the South Asian (24.2), white (25.3) and black (25.5) populations. In general, smoking, obesity and psychosocial stress were significantly more common among those of white ethnicity, whereas diabetes and hypertension were significantly more common among those of black or South Asian ethnicities. Black women were more likely to be physically inactive and obese than the overall population, and South Asian and Chinese women were also less likely to participate in daily physical activity than the overall population. Relative to the white respondents, people with black ethnicity had a 2 -fold higher prevalence of diabetes $(p<0.001)$ and a $44 \%$ higher prevalence of hypertension $(p<0.001)$. Similarly, South Asian people were more likely than white people to have diabetes (prevalence ratio $1.91, p<0.001$ ) or hypertension (prevalence ratio 1.24, $p<0.001$ ) (Table 2).

Overall, Chinese respondents had the most favourable cardiovascular risk factor profile, with $4.3 \%$ of the population reporting two or more major cardiovascular risk factors, followed by the South Asian (7.9\%), white $(10.1 \%)$ and black $(11.1 \%)$ respondents (Table 2). The prevalence of heart disease ranged from a low of $3.2 \%$ among Chinese respondents to a high of 5.2\% among South Asian respondents. The prevalence of stroke ranged from a low of $0.6 \%$ among Chinese respondents to a high of $1.7 \%$ among South Asian respondents. The Chinese population had the lowest overall prevalence of heart disease or stroke (3.8\%) as compared with the black (4.4\%), white (5.7\%) and South Asian (6.6\%) populations (Table 3). Despite having the least favourable overall cardiovascular risk profile, the black population had a relatively low prevalence of heart disease (3.4\%) (Table 3, Figure 1, at the end of this article).

\section{Risk factor and disease profiles by age and sex}

White males were the most likely to smoke and to be obese, irrespective of age (see Figure 2, at the end of this article). The prevalence of smoking was also much higher among white females than their counterparts in other ethnic groups (e.g., $25.5 \%$ for white women v. $4.2 \%$ for Chinese women aged 20 to 44 years). We observed a higher prevalence of diabetes at younger ages among South Asian men and women and among black women than among their white and Chinese counterparts. The data also suggest that stroke may occur at an earlier age, on average, among black males and South Asian females (Figure 3 , at the end of this article).

\section{Interpretation}

In this large population-based study in Ontario, we found striking differences across ethnic groups in the prevalence of cardiovascular risk factors and diseases. The white population had a disproportionately higher prevalence of smoking and obesity, whereas the South Asian and black populations had disproportionately higher prevalences of diabetes and hypertension. People of Chinese origin had significantly lower levels of most cardiovascular risk factors, heart disease and stroke, whereas those of South Asian origin had intermediate levels of risk factors and the highest prevalence of heart disease and stroke. A paradox was observed in the black population, whereby high levels of cardiovascular risk factors were accompanied by a relatively low prevalence of heart disease. A key finding from this study was that the white, South Asian, Chinese and black populations in Ontario had distinct

Table 3: Age- and sex-standardized prevalence of heart disease or stroke or both, by ethnic group, Ontario, Canada, 1996-2007 $(n=163797)^{*}$

\begin{tabular}{|c|c|c|c|c|c|c|c|c|c|}
\hline \multirow[b]{2}{*}{ Outcome } & \multirow{2}{*}{$\begin{array}{c}\text { Overall } \\
n=163797 \\
\text { Prevalence, \% }\end{array}$} & \multicolumn{2}{|c|}{$\begin{array}{c}\text { White } \\
n=154653\end{array}$} & \multicolumn{2}{|c|}{$\begin{array}{c}\text { South Asian } \\
n=3364\end{array}$} & \multicolumn{2}{|c|}{$\begin{array}{l}\text { Chinese } \\
n=3038\end{array}$} & \multicolumn{2}{|c|}{$\begin{array}{c}\text { Black } \\
n=2742\end{array}$} \\
\hline & & Prevalence, \% & $p \dagger$ & Prevalence, \% & pt & Prevalence, \% & $p \dagger$ & Prevalence, \% & $p \dagger$ \\
\hline \multicolumn{10}{|l|}{ Sex, no. } \\
\hline Male & 74978 & 70555 & & 1741 & & 1468 & & 1214 & \\
\hline Female & 88819 & 84098 & & 1623 & & 1570 & & 1528 & \\
\hline \multicolumn{10}{|c|}{ Heart disease } \\
\hline All & 5.0 & 5.1 & 0.36 & 5.2 & 0.82 & 3.2 & $<0.001$ & 3.4 & 0.009 \\
\hline Male & 5.4 & 5.4 & 1.00 & 5.2 & 0.81 & 3.8 & 0.032 & 2.5 & $<0.001$ \\
\hline Female & 4.7 & 4.7 & 1.00 & 5.2 & 0.66 & 2.7 & 0.001 & 4.2 & 0.61 \\
\hline \multicolumn{10}{|l|}{ Stroke } \\
\hline All & 1.1 & 1.1 & 0.94 & 1.7 & 0.28 & 0.6 & 0.008 & 1.3 & 0.68 \\
\hline Male & 1.1 & 1.1 & 1.00 & 1.1 & 0.97 & 0.5 & 0.015 & 1.4 & 0.51 \\
\hline Female & 1.2 & 1.2 & 1.00 & 2.2 & 0.25 & 0.8 & 0.15 & 1.1 & 0.91 \\
\hline \multicolumn{10}{|c|}{$\begin{array}{l}\text { Heart disease } \\
\text { or stroke }\end{array}$} \\
\hline All & 5.7 & 5.7 & 0.54 & 6.6 & 0.22 & 3.8 & $<0.001$ & 4.4 & 0.048 \\
\hline Male & 6.0 & 6.0 & 1.00 & 6.0 & 0.98 & 4.1 & 0.010 & 3.8 & 0.023 \\
\hline Female & 5.4 & 5.4 & 1.00 & 7.1 & 0.15 & 3.5 & 0.003 & 4.9 & 0.58 \\
\hline
\end{tabular}

*Data were derived from the Ontario components of Statistics Canada's National Population Health Survey and Canadian Community Health Surveys. Estimates were age- and sex-standardized to the 2001 Ontario Census population using five-year age categories and were weighted by the survey sample weight. tBootstrap methods were used to derive $p$ values for comparisons of ethnic-specific estimates with overall estimates. 
cardiovascular risk profiles, which suggests the need for the development of ethnic-specific cardiovascular risk prevention programs and health services in Canada.

The overall prevalence of heart disease and stroke was highest among South Asian respondents and lowest among Chinese respondents. This is consistent with results from the Study of Health Assessment and Risk in Ethnic groups living in three Ontario cities, which found a disproportionately higher prevalence of cardiovascular disease among South Asian participants (10.7\%) than among Chinese participants $(2.4 \%))^{3}$ Our study findings are also consistent with a previous study of 1.2 million deaths in Canada, which showed that the rates of cardiovascular-related mortality were highest in the South Asian population, followed by the European and Chinese populations. ${ }^{17}$ The high risk of heart disease that we observed for the South Asian respondents might be explained in part by their relatively high susceptibility to insulin resistance and the metabolic syndrome, which is characterized by central obesity, glucose intolerance, a poor lipid profile and diabetes. ${ }^{18-20}$ In our study, South Asian respondents were 1.91 times more likely to have diabetes than white respondents, a result similar to that reported in a previous investigation of biochemically measured diabetes. ${ }^{3}$

A noteworthy observation in our study was the much lower levels of smoking observed among Chinese (8.7\%) and South Asian $(8.6 \%)$ respondents living in Ontario relative to rates documented in China $(28.9 \%)^{21}$ and India $(15.6 \%) .^{22}$ These findings might be attributable in part to a "healthy immigrant" effect and/or Canada's tougher antismoking policies. In Ontario, physical inactivity was most prevalent among Chinese and South Asian respondents. Although people of these ethnic backgrounds have a lower average body mass index than white people, there is growing evidence that they also tend to have a higher percentage of body fat and a greater risk of cardiovascular events at a lower body mass index. ${ }^{23,24}$ As such, regular exercise and maintenance of a healthy weight are important goals for South Asian and Chinese people.

Despite a higher prevalence of most traditional cardiovascular risk factors, the black population had a lower prevalence of heart disease than the overall population. This paradox might be explained, at least in part, by the lower levels of smoking and psychosocial stress reported by this group. Populations of African descent also have lower levels of plasma fibrinogen than the general population, which would decrease their risk of thrombosis and clinical events. ${ }^{25,26}$ The relatively low prevalence of heart disease among black respondents might also be a function of differential survival rates for this group relative to the other ethnic groups. For example, studies in the United States have reported that black people undergo fewer invasive cardiac procedures and tend to have poorer survival rates after myocardial infarction than white people, ${ }^{27-29}$ which could lead to a survival bias and apparent paradox of lower prevalence of heart disease if black patients die relatively soon after developing heart disease.

\section{Limitations}

The cross-sectional design of this study limited our ability to draw conclusions about the causal relationships between risk factors and disease. Another limitation of the study was that our analyses were based on data, including ethnicity, that were self-reported rather than measured. There is no "gold standard" for defining ethnicity, and self-reported ethnicity is the best measure currently available. We were also unable to analyze variables that were not routinely collected in the surveys (e.g., information about lipids, waist-to-hip ratio and family history of cardiovascular diseases). Nevertheless, these limitations were counterbalanced by the much larger sample size that was possible in this study as compared with most previous studies involving direct physical measurements. Furthermore, the findings presented here are congruent with those based on direct measurements and are generally consistent with those of earlier comparisons of two or three ethnic groups. We recognize that diversity also exists within each of the four ethnic groups and that the ethnic differences presented in this study are the results of complex interactions between and among genetics, lifestyle, socio-economic status, provision of health care and reporting. Further examination of these interactions is necessary.

\section{Conclusion}

Despite universal access to health care, ethnic groups living in Ontario differed markedly in their cardiovascular risk profiles. Awareness of these differences will become increasingly important as ethnic minority groups come to represent a larger proportion of the Canadian population. Although Canada is one of the most ethnically diverse countries in the world, relatively little research has been done on ethnic differences in cardiovascular health, and most cardiovascular prevention programs and policies are targeted to the general population and have been based on studies typically involving the white population. Our findings suggest that there may be a need to develop ethnically tailored strategies for preventing cardiovascular risk factors in Canada. Developing strategies for preventing diabetes and hypertension that are targeted specifically to high-risk South Asian and black populations, designing obesity-prevention programs for black women and for white people, and promoting physical activity among South Asian and Chinese people and black women are some examples of approaches that might help to reduce ethnic disparities in cardiovascular risk factors and the burden of cardiovascular disease.

This article has been peer reviewed.

Competing interests: None declared.

Contributors: Maria Chiu conceived the study, performed the analyses and prepared the first draft of the manuscript. All authors interpreted the data, critically revised the manuscript for important intellectual content and approved the final version of the manuscript. Jack Tu provided overall supervision. Administrative, technical and logistic support was provided by all authors.

Acknowledgements: The authors acknowledge that the data used in this publication are from Statistics Canada's National Population Health Survey and Canadian Community Health Survey. The authors thank all the participants of these surveys, as well as the staff from Statistics Canada who assisted in the collection and management of the survey data. The authors also thank David Henry, Baiju Shah, Douglas Lee and Gordon Moe for providing comments on an earlier version of the manuscript, and Minh Duong-Hua and Sue Schultz for assistance with survey methodology. 
Funding: This study was supported by an operating grant from the Heart and Stroke Foundation of Ontario (HSFO) to the Institute for Clinical Evaluative Sciences (ICES), a Canadian Institutes of Health Research (CIHR) Frederick Banting and Charles Best Canada Graduate Scholarship Doctoral Award to Maria Chiu and a CIHR Team Grant in Cardiovascular Outcomes Research. ICES is funded by the Ontario Ministry of Health and Long-Term Care. Peter Austin is supported by a Career Investigator Award from the HSFO. Doug Manuel is supported by a CIHR/Public Health Agency of Canada Chair in Applied Public Health. Jack Tu is supported by a Canada Research Chair in Health Services Research and a Career Investigator Award from the HSFO.

The study results and conclusions are those of the authors and should not be attributed to any of the funding or sponsoring agencies. No endorsement by ICES or the Ontario Ministry of Health and Long-Term Care is intended or should be inferred. All decisions regarding study design, data analysis and publication were made independent of the funding agencies. Maria Chiu and Jack Tu had full access to the study data and take final responsibility for the decision to submit this manuscript for publication.

\section{REFERENCES}

1. Murray CJ, Lopez AD. Mortality by cause for eight regions of the world: Global Burden of Disease Study. Lancet 1997;349:1269-76.

2. Yusuf S, Reddy S, Ounpuu S, et al. Global burden of cardiovascular diseases: part I: general considerations, the epidemiologic transition, risk factors, and impact of urbanization. Circulation 2001;104:2746-53.

3. Anand SS, Yusuf S, Vuksan V, et al. Differences in risk factors, atherosclerosis, and cardiovascular disease between ethnic groups in Canada: the Study of Health Assessment and Risk in Ethnic groups (SHARE). Lancet 2000;356:279-84.

4. Lip GY, Barnett AH, Bradbury A, et al. Ethnicity and cardiovascular disease prevention in the United Kingdom: a practical approach to management. J Hum Hypertens 2007;21:183-211.

5. Mensah GA, Mokdad AH, Ford ES, et al. State of disparities in cardiovascular health in the United States. Circulation 2005;111:1233-41.

6. Yusuf S, Hawken S, Ounpuu S, et al. Effect of potentially modifiable risk factors associated with myocardial infarction in 52 countries (the INTERHEART study) case-control study. Lancet 2004;364:937-52.

7. Visible minority groups, 2006 counts, for Canada, provinces and territories Ottawa (ON): Statistics Canada; 2006. Available: http://www12.statcan.ca/census -recensement/2006/dp-pd/hlt/97-562/pages/page.cfm?Lang=E\&Geo=PR\&Code=01 $\&$ Table $=1 \&$ Data $=$ Count $\&$ Sex $=$ Both $\&$ StartRec $=1 \&$ Sort $=7 \&$ Display $=$ Page $\&$ CSD Filter=5000 (accessed 2010 Mar. 31).

8. Desmeules M. Appendix A: overview of national population health and Canadian community health surveys. BMC Womens Health 2004;4(Suppl 1):S35.

9. Thomas S, Wannell B. Combining cycles of the Canadian Community Health Survey. Health Rep 2009;20:53-8

10. Canadian community health survey. Cycle 1.1 derived variable (DV) specification 2001. Ottawa (ON): Statistics Canada; 2001. Available: https://ozone.scholarsportal .info/bitstream/1873/207/5/cchs2000-2001dv.pdf (accessed 2009 Jul. 28).

11. Lee DS, Chiu M, Manuel DG, et al. Trends in risk factors for cardiovascular disease in Canada: temporal, socio-demographic and geographic factors. CMAJ 2009; 181:E55-66

12. Bazzano LA, He J, Ogden LG, et al. Fruit and vegetable intake and risk of cardio- vascular disease in US adults: the first National Health and Nutrition Examination Survey Epidemiologic Follow-up Study. Am J Clin Nutr 2002;76:93-9.

13. Efron B, Tibshirani RJ. An introduction to the bootstrap. Boca Raton (FL): Chapman \& Hall/CRC; 1993.

14. Rust KF, Rao JN. Variance estimation for complex surveys using replication techniques. Stat Methods Med Res 1996;5:283-310.

15. BOOTVAR user guide (BOOTVAR 3.1 SAS version). Ottawa (ON): Statistics Canada. Available: http://prod.library.utoronto.ca/datalib/codebooks/cstdli/gss /gss18/sasbootdoc_eng.pdf (accessed 2009 Nov. 28).

16. Ontario population files. In: Census of Canada, 2001. Ottawa (ON): Statistics Canada; 2001

17. Sheth T, Nair C, Nargundkar M, et al. Cardiovascular and cancer mortality among Canadians of European, south Asian and Chinese origin from 1979 to 1993: an analysis of 1.2 million deaths. CMAJ 1999;161:132-8.

18. McKeigue PM, Shah B, Marmot MG. Relation of central obesity and insulin resistance with high diabetes prevalence and cardiovascular risk in South Asians. Lancet 1991;337:382-6.

19. Sohal PS. Prevention and management of diabetes in South Asians. Can J Diabetes 2008;32:206-10.

20. Yusuf S, Reddy S, Ounpuu S, et al. Global burden of cardiovascular diseases: Part II: variations in cardiovascular disease by specific ethnic groups and geographic regions and prevention strategies. Circulation 2001;104:2855-64.

21. WHO 2009 statistical tables: country health information profiles. Geneva (Switzerland): World Health Organization; 2009. Available: www.wpro.who.int /NR/rdonlyres/ECDFFD21-C259-4431-8F30-7A93E363F2EA/0/42StatisticalTables 2009.pdf (accessed 2009 Dec. 1).

22. Jindal SK, Aggarwal AN, Chaudhry K, et al. Tobacco smoking in India: prevalence, quit-rates and respiratory morbidity. Indian J Chest Dis Allied Sci 2006;48:37-42.

23. Razak F, Anand SS, Shannon H, et al. Defining obesity cut points in a multiethnic population. Circulation 2007;115:2111-8

24. Deurenberg-Yap M, Schmidt G, van Staveren WA, et al. The paradox of low body mass index and high body fat percentage among Chinese, Malays and Indians in Singapore. Int J Obes Relat Metab Disord 2000;24:1011-7.

25. Chaturvedi N, McKeigue PM, Marmot MG. Relationship of glucose intolerance to coronary risk in Afro-Caribbeans compared with Europeans. Diabetologia 1994;37:765-72.

26. Cappuccio FP. Ethnicity and cardiovascular risk: variations in people of African ancestry and South Asian origin. J Hum Hypertens 1997;11:571-6.

27. Sonel AF, Good CB, Mulgund J, et al. Racial variations in treatment and outcomes of black and white patients with high-risk non-ST-elevation acute coronary syndromes: insights from CRUSADE (Can Rapid Risk Stratification of Unstable Angina Patients Suppress Adverse Outcomes With Early Implementation of the ACC/AHA Guidelines?). Circulation 2005;111:1225-32.

28. Kressin NR, Petersen LA. Racial differences in the use of invasive cardiovascular procedures: review of the literature and prescription for future research. Ann Intern Med 2001;135:352-66.

29. Peterson ED, Shaw LK, DeLong ER, et al. Racial variation in the use of coronaryrevascularization procedures. Are the differences real? Do they matter? $N$ Engl J Med 1997;336:480-6.

Correspondence to: Dr. Jack V. Tu, Institute for Clinical Evaluative Sciences, G106-2075 Bayview Ave., Toronto ON

M4N3M5; tu@ices.on.ca

See following pages for Figures 1-3. 

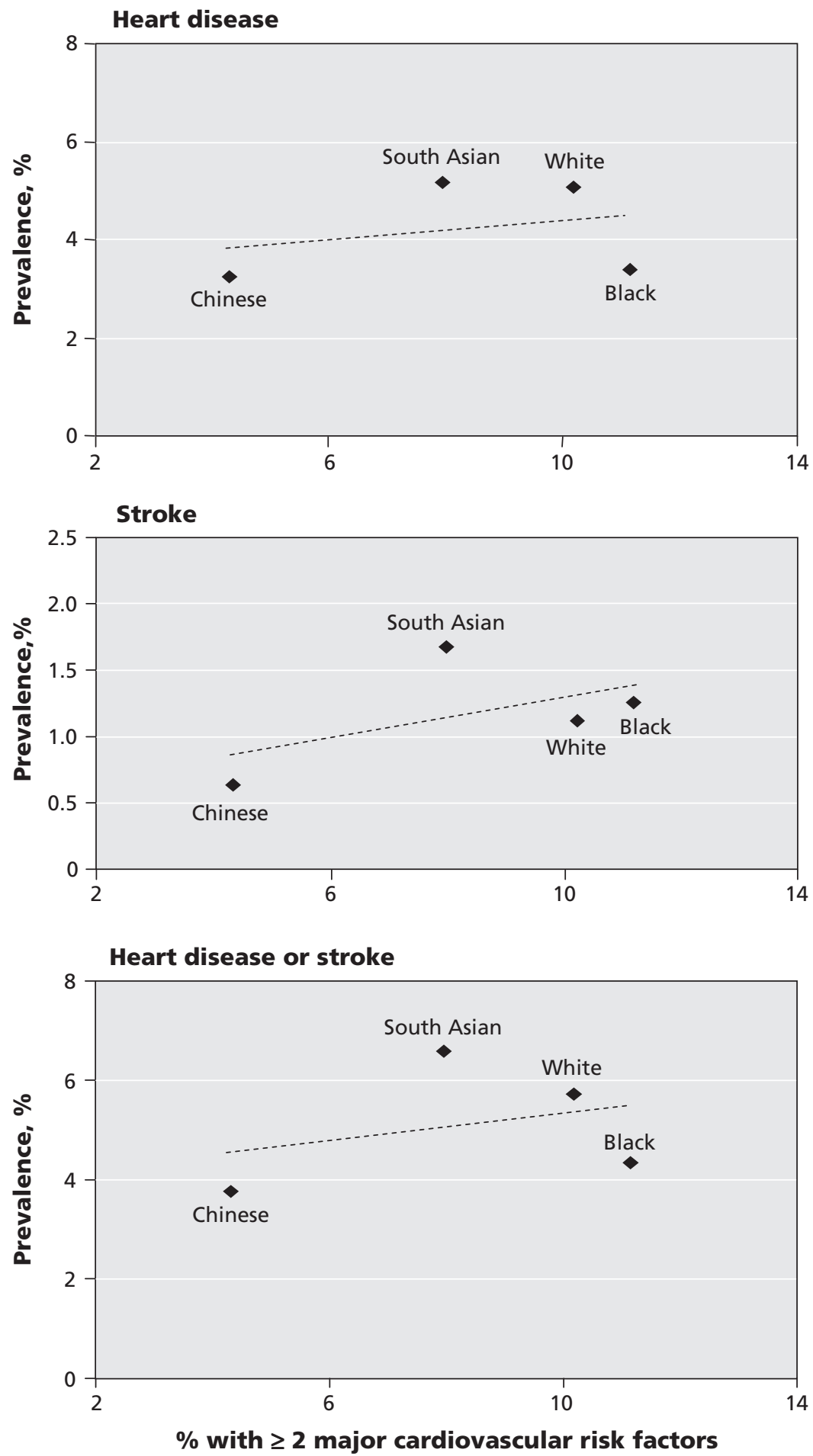

Figure 1: Relation between the percentage of the population with two or more major cardiovascular risk factors and the prevalence of heart disease, stroke, and heart disease or stroke, by ethnic group, Ontario, Canada, 1996-2007. Major cardiovascular risk factors were current smoking, obesity, diabetes mellitus and hypertension. All estimates were age- and sex-standardized to the 2001 Ontario Census using five-year age categories and were weighted by the survey sample weight. Data were derived from the Ontario components of Statistics Canada's National Population Health Survey and Canadian Community Health Surveys. 

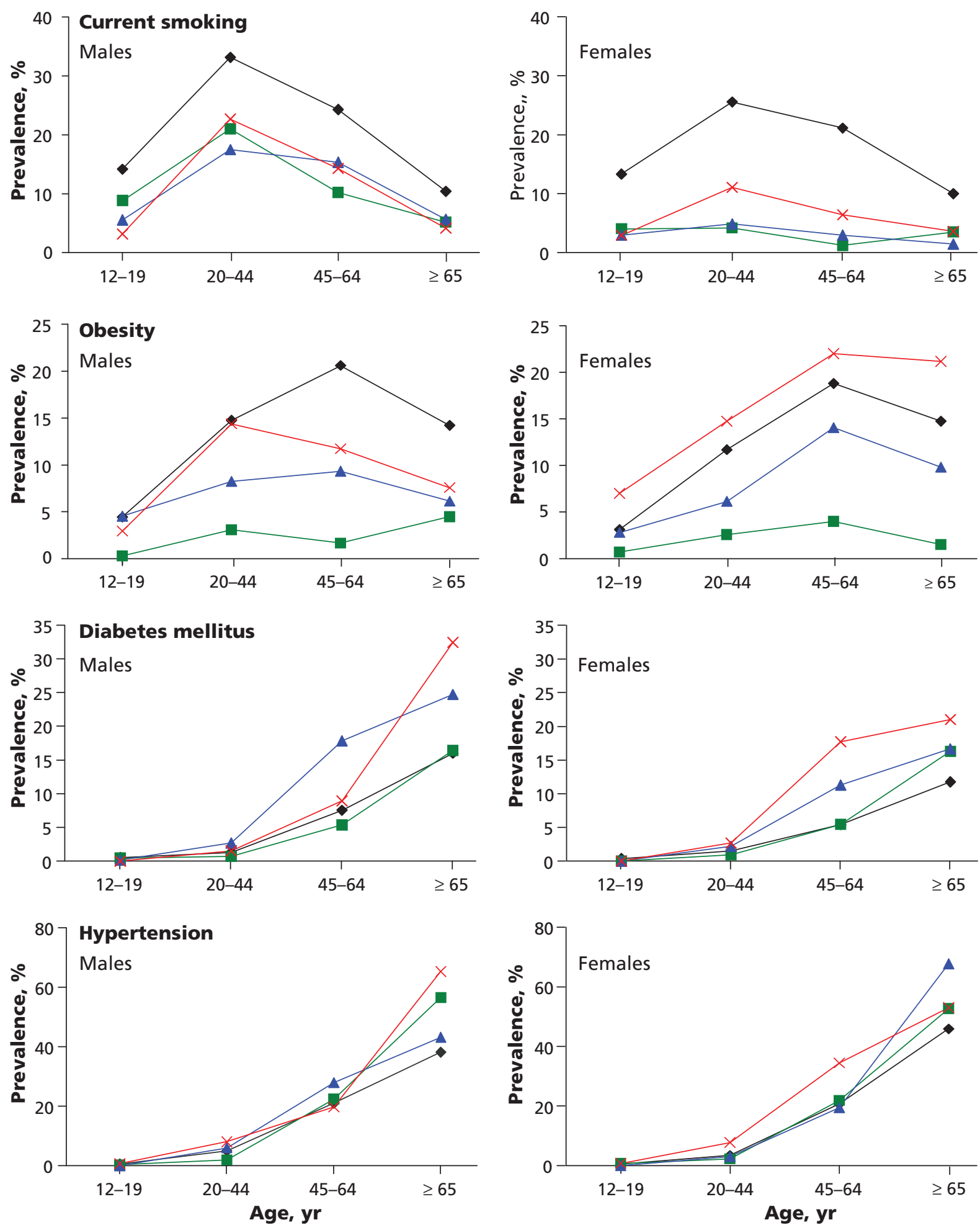

$\rightarrow$ White - Chinese $\rightarrow$ South Asian $\rightarrow$ Black

Figure 2: Age- and sex-specific prevalence of major cardiovascular risk factors, by ethnic group, Ontario, Canada, 1996-2007. Estimates were age-standardized to the 2001 Ontario Census population using five-year age categories and were weighted by the survey sample weight. Data were derived from the Ontario components of Statistics Canada's National Population Health Survey and Canadian Community Health Surveys. 

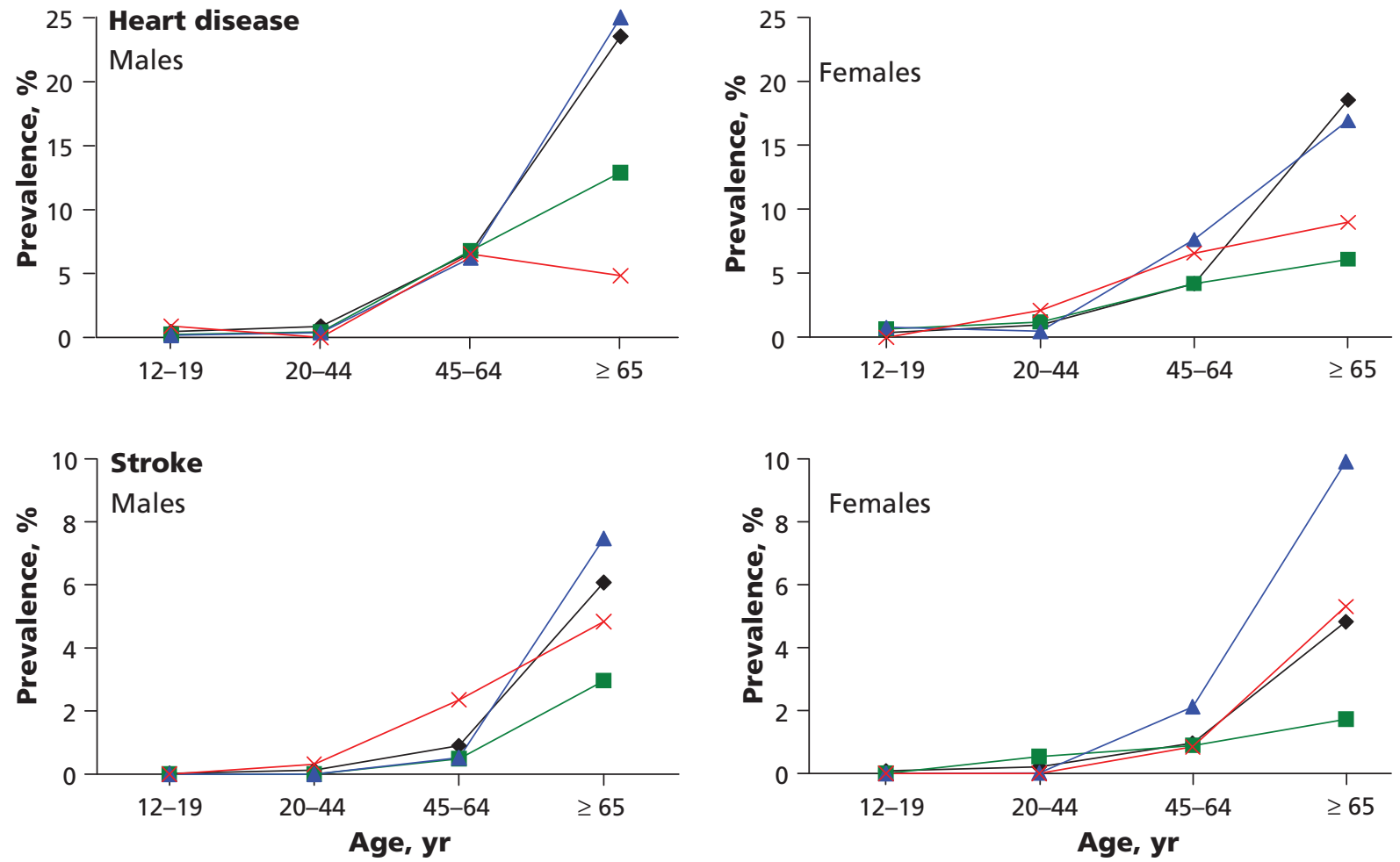

$\rightarrow$ White $\rightarrow$ - Chinese $\rightarrow$ South Asian $\rightarrow$ Black

Figure 3: Age- and sex-specific prevalence of heart disease and stroke, by ethnic group, Ontario, Canada, 1996-2007. Estimates were age-standardized to the 2001 Ontario Census population using five-year age categories and were weighted by the survey sample weight. Data were derived from the Ontario components of Statistics Canada's National Population Health Survey and Canadian Community Health Surveys. 